para indução anestésica implicam na utilização de grandes volumes de propofol. Já para animais com pequeno peso corporal, proporciona indução e recuperação anestésica rápida, se comparada a outros fármacos utilizados para o mesmo fim. Com este estudo foi possível concluir que a via intracelomática, além de ser de fácil aplicação, pode ser utilizada para indução anestésica com propofol; desde que este seja utilizado em altas dosagens, não sendo observados quaisquer sinais de letalidade.

Schmidt-Popazoglo, E.M.S.'; Mangrich-Rocha, R.M.V. ${ }^{2}$; Lange, R.R. ${ }^{3}$
Locatelli-Dittrich, R. '; Cavalheiro, M.L. ${ }^{2}$; Schmidt-Popazoglo, E.M.S. ${ }^{3}$; Tanikawa, C.Y.'; Curotto, S. M. R.'; Ostrowski, M. A. B' ; MangrichRocha, R.M. ${ }^{+}$; Toledo; M.S.'

\section{4 - Avaliação da concentração plasmática dos íons cálcio, sódio e potássio de cágados-pescoço-de- cobra (Hydromedusa tectifera)}

1-Professora da Disciplina de Patologia Clínica Veterinária do Curso de Medicina Veterinária da Universidade do Contestado, Campus Marcilio Dias, Canoinhas-SC

2- Professora Disciplina de Patologia Clínica Veterinária da Pontificia Universidade Católica, Curitiba-PR

3- Professor Departamento de Medicina Veterinária da Universidade Federal do Paraná, Curitiba-PR

O cágado-pescoço-de-cobra (Hydromedusa tectifera) é um animal semi-aquático que vive no fundo da calha de rios e efetua respiraçào pulmonar através de periódicas incursões à superficie. Esta espécie é encontrada no Brasil, entre os estados de Sào Paulo até o Rio Grande do Sul e também no leste do Paraguai, Argentina e no Uruguai. Os animais possuem um pescoço longo e podem chegar a medir até 30 centímetros. A alimentação dos cágados consiste de peixes, insetos aquáticos e anfibios. Com o objetivo de estabelecer um perfil dos valores de eletrólitos que possa ser utilizado como referência para avaliaçôes clínicas de algumas espécies de répteis, realizaram-se as análises da concentração dos íons cálcio, sódio e potássio de 27 cágados-pescoço-de-cobra, mantidos em biotério, provenientes de rios da regiào metropolitana de Curitiba, Paraná. O sangue foi colhido por punção do seio supraoccipital, utilizando-se contenção fisica dos animais. As amostras de sangue foram acondicionadas em tubo com anticoagulante heparina. Imediatamente após a colheita, o sangue foi centrifugado para obtençào do plasma. As amostras foram processadas pelo método de análise de íons seletivos utilizando-se o aparelho modelo ISELAB ${ }^{\mathfrak{i}}$ (DRAKE ${ }^{\mathrm{i}}$ ). As médias e desvios-padrão obtidos foram: Cálcio ( $\mathrm{mg} / \mathrm{dl}) 2,39 \pm 0,77$; Sódio ( $\mathrm{mmol} / \mathrm{l}$ ) $130,41 \pm 8,1 ;$ Potássio (mmol/1) 2,78 $\pm 0,52$. Os íons sódio, potássio e cálcio estão relacionados com a regulaçào da pressào osmótica, equilíbrio ácido-básico, manutenção dos potenciais de membrana, transmissão dos impulsos nervosos e contraçào muscular, exercendo assim importantíssimo papel na homeostase do organismo. A utilização destes parâmetros permite uma avaliaçào segura dos animais doentes, das condições do seu habitat em cativeiro e do impacto ambiental em animais de vida livre.

\section{5 - Valores hematológicos e bioquímicos de grupos de papagaios-de-cara-roxa (Amazona brasiliensis)}

1- Departamento de Medicina Veterinária da Universidade Federal do Paraná, Curitiba-PR

2- Sociedade de Pesquisa em Vida Selvagem e Educação Ambiental (SPVS), Curitiba-PR

3- Universidade do Contestado (UnC), Canoinhas-SC

4- Pontifícia Universidade Católica do Paraná, Curitiba-PR

O papagaio-de-cara-roxa (Amą̧ona brasiliensis) é uma espécie encontrada somente na faixa litorânea que abrange o sul de São Paulo, o litoral paranaense e o norte de Santa Catarina. A espécie está ameaçada de extinção, sendo protegida no Brasil por lei Federal. Os exames hematológicos (eritrograma e leucograma) e de proteína plasmática total foram realizados em 22 filhotes sadios, com idade média de 40 dias e de vida livre, e em cinco animais adultos 